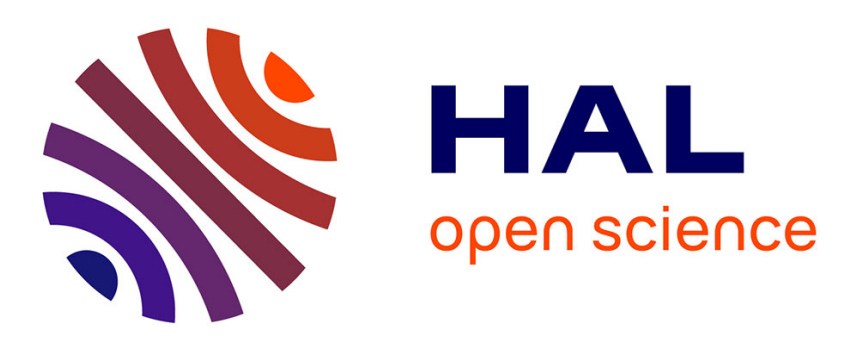

\title{
Joint faults detection in LV switchboard and its global diagnosis, through a Temperature Monitoring System.
} Kahan N'Gouan N'Guessan, Jean-Pierre Rognon, Eric Jouseau, Gilles Rostaing, Florence François

\section{- To cite this version:}

Kahan N'Gouan N'Guessan, Jean-Pierre Rognon, Eric Jouseau, Gilles Rostaing, Florence François. Joint faults detection in LV switchboard and its global diagnosis, through a Temperature Monitoring System.. POWERENG2007, Apr 2007, Setubal, France. pp.736-741. hal-00142629

\section{HAL Id: hal-00142629 \\ https://hal.science/hal-00142629}

Submitted on 20 Apr 2007

HAL is a multi-disciplinary open access archive for the deposit and dissemination of scientific research documents, whether they are published or not. The documents may come from teaching and research institutions in France or abroad, or from public or private research centers.
L'archive ouverte pluridisciplinaire HAL, est destinée au dépôt et à la diffusion de documents scientifiques de niveau recherche, publiés ou non, émanant des établissements d'enseignement et de recherche français ou étrangers, des laboratoires publics ou privés. 


\title{
Joint faults detection in LV switchboard and its global diagnosis, through a Temperature Monitoring System.
}

\author{
Kahan N'guessan (1, 2), Eric Jouseau (2), Jean-Pierre Rognon (1), Gilles Rostaing (1), Florence François (1) \\ Laboratoire d'Electrotechnique de Grenoble, France (1), Schneider-Electric Services division (2) \\ E-mail: kahan.n-guessan@schneider-electric.com
}

\begin{abstract}
-
The paper deals with an entire system of monitoring and diagnosis of $L V$ switchboards based on the measurements of currents, ambient temperatures and local temperatures of electrical joints. This system meets the needs to prevent the breakdowns of LV switchboards, which, although rare, can involve huge financial and human loss. The thermal measurements are done by wireless thermal sensor. The measured data are transmitted via internet and collected in a server, to be centrally processed. This centralized data processing includes a local detection of failures and a global diagnosis which leads to some maintenance recommendations. This paper will focus on, the local detection by comparison with an healthy model, and the global diagnosis using Bayesian network technique. The feasibility of these methods is tested with experimental data and expert's information.
\end{abstract}

\section{INTRODUCTION}

The switchboard is a key element of any electrical installation. It incorporates devices designed to distribute electrical power and protect circuits and people. It is a critical element to the dependability of an electrical installation. A breakdown of the switchboard although rare could be catastrophic because of the critical nature of some of the supplied systems (airport, hospital) and the high costs associated with failures. Therefore, LV switchboard users need to detect and solve the problems before failures appear. Alternatively, even in case of failure, they need to diagnose properly and rapidly the failure's causes in order to eliminate them as soon as possible. An inquiry to Schneider-Electric worldwide experts gives the following failure distribution (Fig.1).

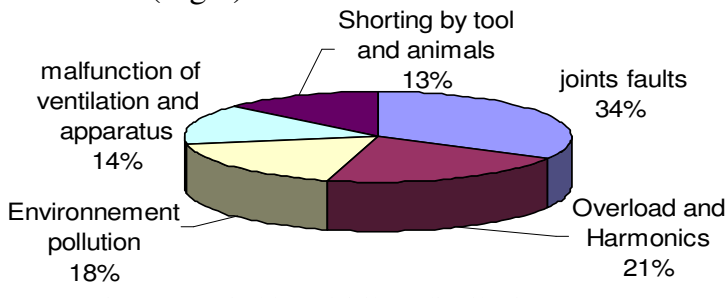

Fig 1 LV switchboard failure distribution.

As we can notice, the first cause of LV switchboards failure is joints fault, which, very often leads to a local overheating. It should be noticed that, the others causes of failure such as overloads, harmonics and malfunction of ventilation are also associated with overheating. Therefore, there is reason to address the detection and diagnosis problems with a monitoring system based on thermal measurements. Up to now, the trend was to carry out frequent thermographic inspections (Once every 2 years) to determine the hot points in one shot. Today, with internet technology, and wireless temperature sensors, it is possible to continuously record the thermal data from sensors. This recording process including wireless temperature sensors and internet server is now available at Schneider Electric. Current measurements could also be available via communicating equipment. This paper aim is to present a monitoring system that uses the data from existing recording process to detect and then diagnose the failures.

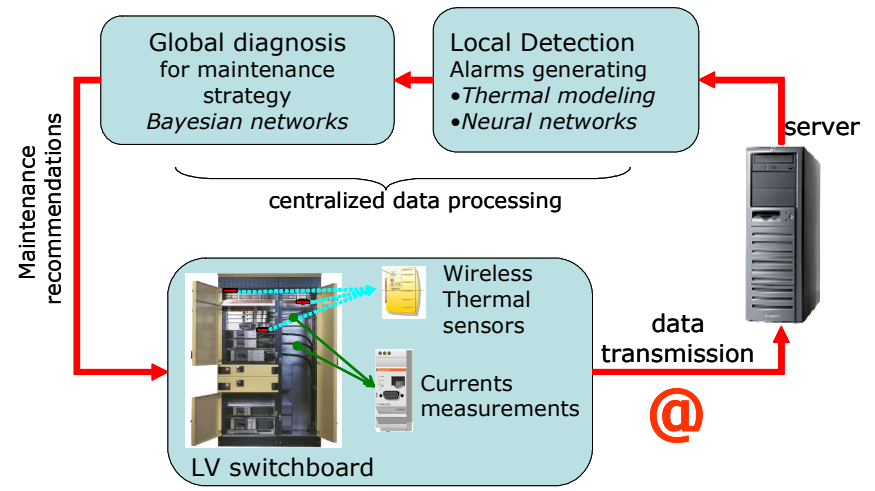

Fig 2. Monitoring and diagnosis system based on wireless thermal sensor and current measurements

As it can be noticed in fig 2, this system is composed of three stages: - First, the data transmission via internet technology, -Second, the detection stage with alarm generation, $\bullet$ Third, the diagnosis itself in order to analyze the alarms generated from the detection stage to make some preventive or curative maintenance recommendations. To ensure a good detection, we need to understand the effects of failure and to know the right sensor placement. This will be addressed in section 1. Section 2 will be devoted to the detection stage, by comparison with a healthy thermal model. Another approach of detection, presented in a previous paper [1], may be to use an estimator based on training process with neural network. We will not go into that in this paper. Section 3 will be dedicated to the global diagnosis stage using the technique of Bayesian networks.

II.

EXPERIMENTS ON ELECTRICAL JOINTS

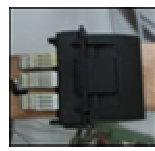

Clamped

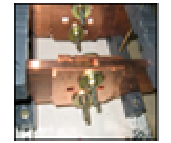

gripped

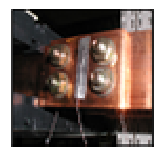

bolted

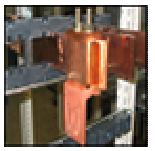

on edge
Fig 3 Different types of electrical joints.

Some experiments, carried out on various types of joints are presented. The goals of these experiments are to analyze the 
thermal changes due to joint failures and to find the right sensors placement. They are related to clamped joint failure effects, joint progressive loosening, joint aging.

\section{A. Effect of Clamped joint failure.}

More and more seen in LV switchboards, clamped joints are used to connect withdrawable apparatuses, which permit to drastically reduce the dismantling time during maintenance operation. The following test has been carried out to illustrate what happens when a clamped joint fails. The test assembly is composed of a Schneider Electric three-phase circuit breaker NS630 installed in a cubicle. We distinguish on fig4 a clamped joint (with 3 clamps) used to connect each phase of the circuit breaker. The test will consist of supplying the circuit breaker with the rated current (520A) in different configurations, with clamped joints composed of 3,2 , and 1 clamp respectively. Thermocouples are used to measure the temperature of selected point numbered from 1 to 13 . We can notice that thermocouples are also placed inside the circuit breaker. Fig4 gives the resulting profile of temperature in which we can see that the reduction of the number of clamp leads to rise the profile of temperature.

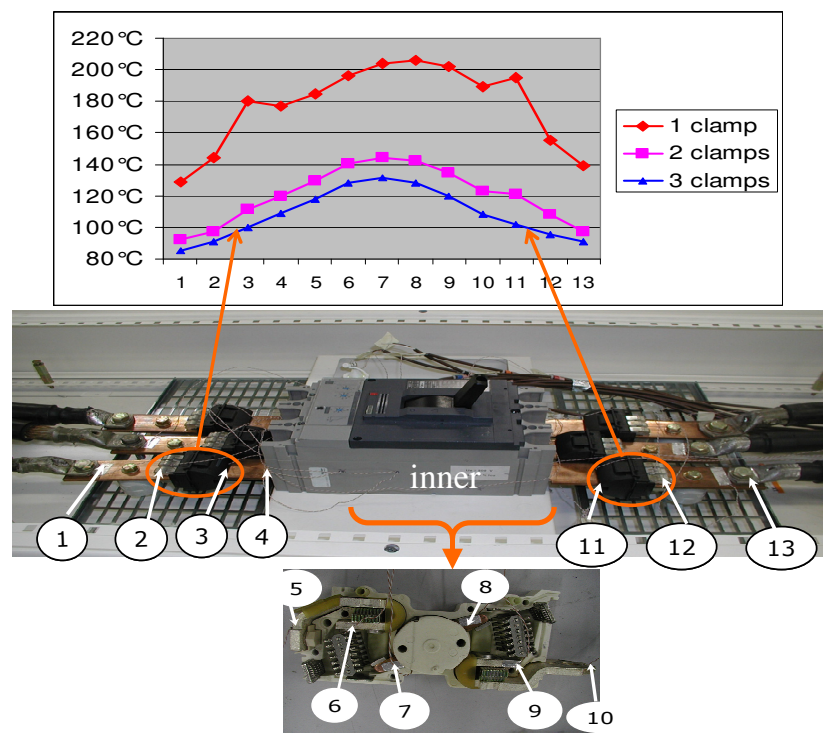

Fig 4 Effets of clamped joints failure

This observation could be explained by the increase of the electrical resistance when reducing the number of clamps (of each joint). Thus, according to Joule Effect when the current passes through, the contact becomes the seat of a stronger creation of heat. The reduction of the number of clamps not only increases the electrical resistance but the thermal resistance too[3]. Thus the heat produced by the circuit breaker has more difficulties to be propagated through the joints. That results in the noticeable difference in temperature at point 2 and 3 or 11 and 12 in both sides of the " 1 clamp" curve. The conclusion of this experiment for sensor placement is that in such a configuration, it is preferable to put the sensor on the side near the circuit breaker. Today, the switchboard architecture does not always permit this placement. Some studies are being carried out at Schneider Electric to integrate the wireless sensor in the clamped joint.

\section{B. Joint progressive loosening}

This experiment has been carried out to analyze the temperature changes generated by a progressive loosening on three common technologies of electrical joints (gripped joint, bolted joint, on edge joint). This test consists in supplying a busbar leading to a joint (gripped, bolted or on edge) with about the rated current. After the stabilization of the temperature, progressive loosening of $1 / 2,1 / 4 \ldots$ of the rated tightening torque is made. The profile of temperature is measured using thermocouples placed along the busbar (fig5)

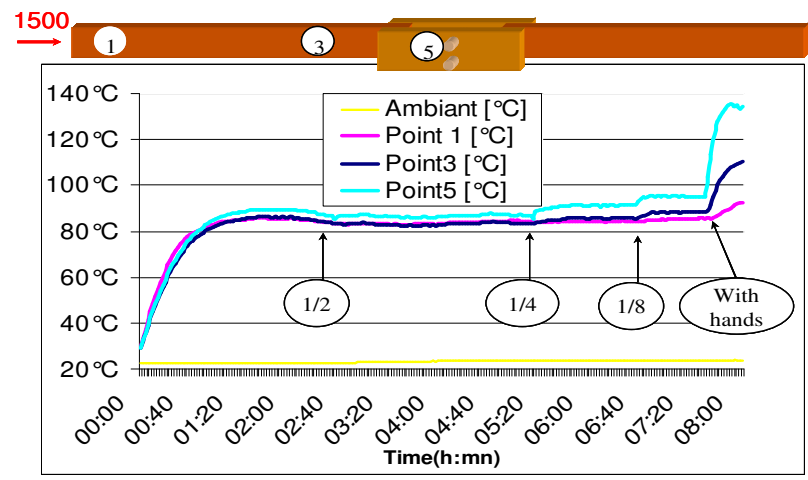

Fig 5 Progressive loosening test assembly and results for the gripped joint.

Point 1: Thermocouple placed at $60 \mathrm{~cm}$, Point3; Thermocouple placed at $20 \mathrm{~cm}$ Point5:Thermocouple placed on the contac;, Ambient: approximately $50 \mathrm{~cm}$ far from the busbar

The results of the test, for the gripped joint (fig 5), show that it is necessary to loosen down to less than $1 / 8$ of its rated torque, $(28 \mathrm{Nm})$ to be able to see a significant overheating. This shows that the electrical resistance of the gripped joint does not vary enormously during loosening until $4 \mathrm{Nm}$ (around 1/8 of the rated torque), from which it increases exponentially. Since the heating results from Joule Effect, heating increases with electrical resistance[4]. With regard to the other types of joints, this experiment gives similar results. The on edge joint distinguishes itself somewhat by greater joint electrical resistance, more overheating being generated on it (fig 6). The overheating attenuation can be calculated as the ratio of overheating on the joint (point 5) to the overheating $200 \mathrm{~mm}$ far from the joint (point 3).

$\begin{array}{lccc} & \text { Gripped } & \text { Bolted } & \text { On edge } \\ \text { Rated torque (RT) } & 28 \mathrm{Nm} & 50 \mathrm{Nm} & 28 \mathrm{Nm} \\ \text { Busbar cross-section }\left(\mathrm{mm}^{2}\right) & 80^{*} 10 & 60^{*} 10 & 60^{*} 10 \\ \text { Current } & 1800 \mathrm{~A} & 1500 \mathrm{~A} & 1500 \mathrm{~A} \\ \text { Time constant (minutes) } & 45 & 40 & 42 \\ \text { Overheating with } 1 / 4 \mathrm{RT} & 4^{\circ} \mathrm{C} & 3^{\circ} \mathrm{C} & 12^{\circ} \mathrm{C} \\ \text { Attenuation at } 20 \mathrm{~cm} & 47 \% & 53 \% & 55 \%\end{array}$

Fig 6 Result of progressive loosening test, on the three types of joints.

There is $52 \%$ attenuation on average of the overheating on the three types of joints (gripped, bolted, On edge) at $200 \mathrm{~mm}$ from the joint (point 3 ). Through the observations made during this experiment, we can assume that:

To observe a considerable rise in temperature the joint has to be loosened down 1/8 of the rated torque. Moreover, to detect the heating effect of the loosening of a joint the sensor has to be placed less than $200 \mathrm{~mm}$ from the joint. 


\section{Joint Aging}

In this test, the aging process of the joints is investigated and then analysis is made of the influence of the current level on this aging. The test is made on the gripped joint tightened beforehand at $1 / 8$ of its rated torque to accelerate the aging process. The experiment consists of supplying the busbar with cycles of currents. Each cycle consisted of two hours of current supply followed by a cool-off period of about two and a half hours. The e-hour duration was chosen to allow the busbar to reach a stable temperature, after which the busbar was allowed to cool down to ambient temperature. For the first 12 cycles, the busbar was supplied with a current of $1800 \mathrm{~A}$, after which it was supplied with a current of 2200A until cycle 32. Fig 7 gives the temperature rise calculated as the difference of temperature between point 5 (on the contact) and point 2 (400 $\mathrm{mm}$ far from the contact). This curve shows that the number of cycles affects the joint contact by the rise of the local heating.

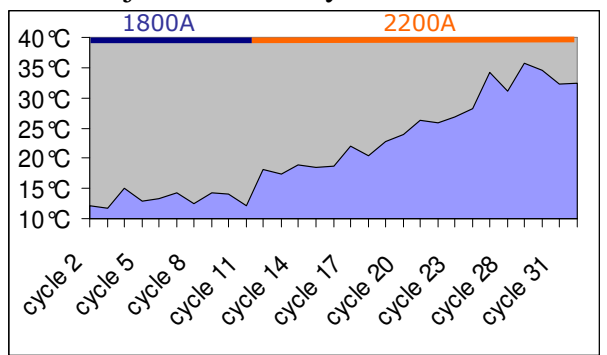

Fig 7 Aging test on gripped joint

From cycle 1 to cycle 12, the contact has not aged significantly From cycle 12 to cycle 32 with a supply current of $2200 \mathrm{~A}$ (about 1.5 time of the rated current), a steady increase of the overheating can be observed. Therefore, the joint indeed ages in time with the number of cycles. This ageing process is accelerated by overloads. The ageing process could be explained by two reasons: The oxidation of the joint interface metal, which contributes to increase the joint resistance, with an oxidation speed accelerated by temperature rise due to overloads. The thermo-mechanical effects involving stressrelaxation phenomena associated with cycles, which reduces contact force and consequently increases contact resistance [2]. Through the previous experiments, it is apparent that an electrical joint holds onto its failure state once the failure appears, and could get worse under certain conditions. In the following section, a technique of detection of failures using a comparison with a healthy model is tested.

\section{AUTOMATIC DETECTION OF ABNORMAL HEATING BY COMPARISON WITH A HEALTHY THERMAL MODEL.}

\section{A. Principle of modeling and automatic detection.}

At Schneider Electric, there is an in-house, thermal computation software based on a representation of the LV switchboard as a network of nodes connected to each other by thermal conductance (convective, conductive, and irradiative). The principle of modeling is a nodal method and the calculations are done by finite difference. The software takes into account the electric aspect of the problem through electrical resistance. This model is suitable for modeling conduction phenomena, which represents 60 to $70 \%$ of heat exchange phenomena in the switchboard.

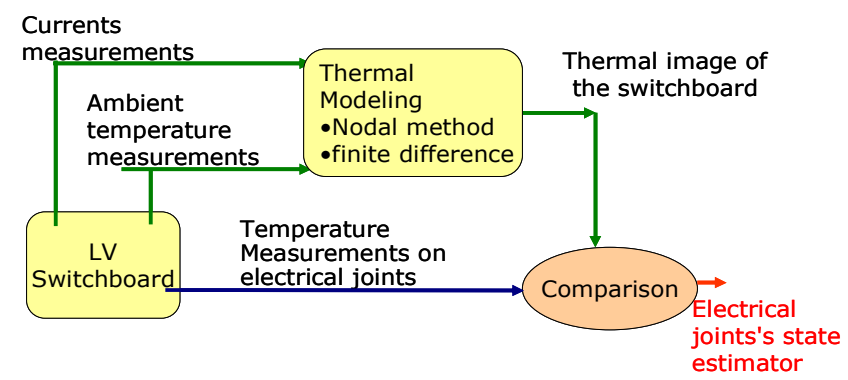

Fig 8 Electrical joints's states estimator.

This software can be used to have a thermal modeling of the switchboard (Schneider Electric model library). The inputs of the model are the currents and the ambient temperature of the switchboard. The output of the model is the temperature on several selected electrical joints. It should not be forgotten that most of the time the model result is a bit different from the experimental results. For reducing the disparity between the model and the real system, something important to do after modeling is to make the model in line with an experimental measurement from a healthy switchboard. This is done by tuning some parameters as joint electrical resistance, thermal resistance and heat exchange coefficient. This tuning has to be done on the operating currents range. Then the fitted model is used as a reference of a healthy switchboard. Over time, the drift of the difference from the temperature measured in comparison with the corresponding temperature from the model is an estimator of the joints state (fig8). In the following paragraph we will test this method on a switchboard in real-life situation.

\section{B. Example of a real switchboard tested and modeled..}

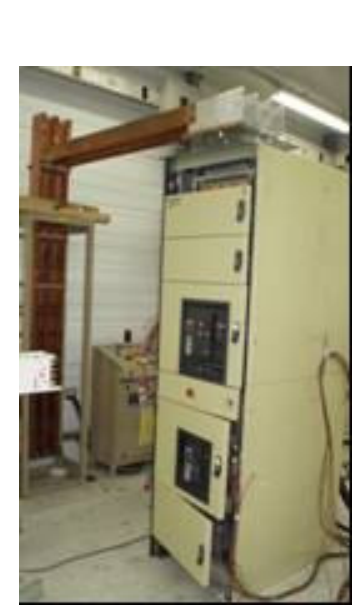

Apparatuses with nominal currents of $3200 \mathrm{~A}$ and $1600 \mathrm{~A}$ respectively

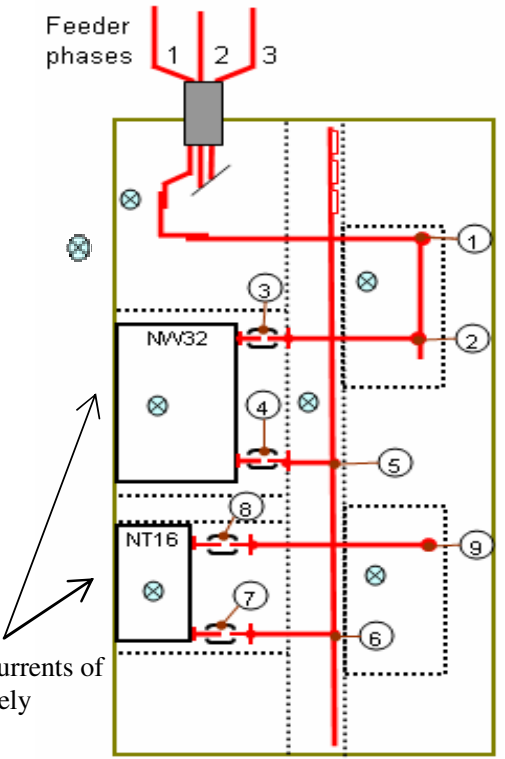

Q: Points of measurement of compartment ambient temperature. : Busbar with bolted joint. =: Clamped joint.

: Compartment. (1): Points of measurement of joint temperature.

Fig 9 Real LV switchboard in experiment, with associated busbar circuit and measured points. 
Fig 9 shows a real switchboard in the experiment (left), with one of the three associated busbar circuit phases (right). Thermocouples have been put on some joints (including bolted and clamped). Ambient temperatures of selected compartments have been measured via thermocouples too. First, the switchboard has been supplied by a current of $1000 \mathrm{~A}$ the thermal stabilization occurred after a time period of about four and a half hours. Fig 10 gives the comparison between temperatures performed by the modeling software after tuning, and the real values measured on the joints. It can be noticed on fig 10 that the temperatures resulting from modeling are very close to the experimental ones. The average relative error between the model and the experiment is $1 \%$ with a maximum of $2 \%$ on points $2,4,6$ and 7 . To verify the validity of the model, we choose to supply the switchboard with another range of current $(1600 \mathrm{~A})$ in order to make the same comparison.

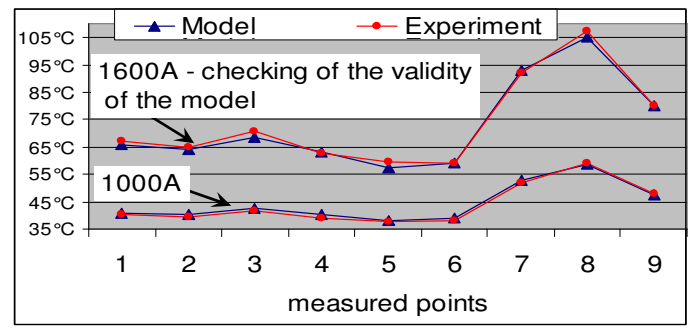

Fig 10 Comparison between the model and the experiment after tuning with a test at $1000 \mathrm{~A}$, and validation of the model with a test at 1600A.

The model has been run without changing anything on the modeling parameters apart from the input current of 1600A. The graph also gives the comparison between the model and the experiment with $1600 \mathrm{~A}$ of supplied current. The average relative' error between the model and the experiment is $2 \%$ with a maximum of $4 \%$ reached on the point 5 . According to these results, the model can be qualified as valid. Now this model can be used as a valid reference. In order to check that the model can detect an abnormal heating, an experiment has been done with joint 9 loosened at $1 / 8$ of its rated torque. The supplied current was $1000 \mathrm{~A}$. We can see on fig 11 that the faulty point 9 is abnormally hot, compared to the healthy model. And the others faultless points are close to the model, apart from the point 8 a bit affected by the hot temperature on point 9 through heat exchange.

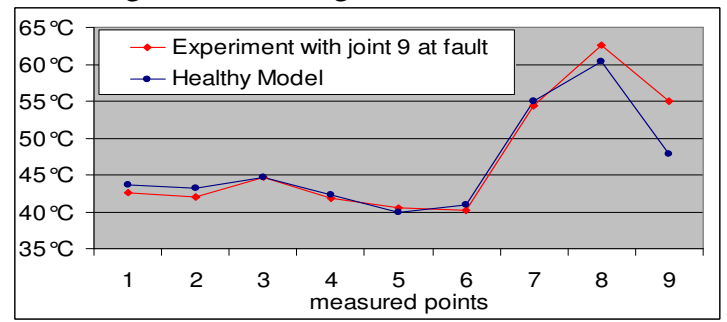

Fig 11 Comparison between the model and a test with failure of the joint 9 .

\section{DIAGNOSIS OF FAILURES BASED ON BAYESIAN NETWORKS.}

Once the failure has been detected, the following stage should be the diagnosis itself, that is to know the cause of the failure. In the present methodology, when a failure occurs, the experts go on site to seek some indications guiding them to find the causes of failure. More specifically, knowing the failure, they seek the indications in a probable family of indications, and work by an elimination process to find the most likely cause. Since experts have a probabilistic and inference based reasoning, one of the natural ways to represent and to automate this reasoning is by a Bayesian Networks (BN) approach. BN also allows predictive diagnosis, ie knowledge of consequences to LV switchboard working conditions, early drift detection. The second reason in support of the $\mathrm{BN}$ choice is that in numerous industrial diagnosis problems, BN showed encouraging results [14].

\section{A. Bayesian Network.}

It is to the Bayes rule that we owe the term "Bayesian". BN is the research results of J.Pearl and a Danish team of Aalbord University [5]. BN is a causal graph making it possible to bind a set of effects to their causes. BN combines tables of conditional probabilities with the causal graph that enables a probabilistic reasoning on the graph to be accomplished. With $\mathrm{BN}$ it is possible reason in the two directions: the calculations of the probability of causes knowing the effects but also the probabilities of the effect knowing the causes. The implementation of a $\mathrm{BN}$ is done in two stages:

- Knowledge acquisition and graph creation.

- Conditional probabilities table (CTP) filling.

Several internal documents in Schneider Electric deal with LV switchboard failure causes. The reading of these documents [6]-[7]-[8]-[9] enables us to get an idea of the parameters acting on the operation of LV switchboard and which could be useful for its diagnosis. This information has been supplemented with various discussions with experts. Indeed six experts were questioned on the possible causes of degradations of LV switchboards and three among these experts intervened in the construction and the final validation of the BN. With regard to $\mathrm{BN}$ implementation, we use MATLAB Toolbox, FullBNT-1.0.2 developed by Kervin Murphy at Berkeley [10].

B. Case of application: Example extracted from the whole graph. In this section a concrete example of $\mathrm{BN}$ is given. This example is drawn from a complete BN of the LV switchboard. The choice of this part of the graph was guided by a preoccupation with simplification. Thus, a part of the graph with variables that have a reduced number of states was taken. These variables have been considered as binary. By considering binary variables, we place ourselves on a level of diagnosis, which can be interpreted as a "roughing" step in diagnosis.

1) Information coming from the experts:

- An increase in the external temperature (ET) automatically involves an increase in the LV switchboard ambient temperature. ${ }^{-}$A ventilation obstruction (VO) makes the circulation of fresh air difficult. Hence, with a VO additional heating of the internal air of the switchboard is observed. • The rated current is distributed in the different circuits of the LV switchboard by taking into account a multiplying factor called the diversity factor (DF), given by the manufacturer. The failure to respect this requirement leads to a rise in the internal 
temperature of the table. - Abnormal heating $(\mathrm{AH})$ is a local phenomenon, which does not contribute very much to the heating of the ambient temperature of the switchboard, but rather contributes to the degradation of the insulators (ID) that are close to the hot point. - A high internal temperature (IT) has two consequences, which are the tripping of thermal release (TTR) of circuit breakers or the degradation of insulators that are under additional thermal stresses.

2) Graph construction and CPT filling.

All this information enables us to identify the variables and build the causality graph (Fig12). The experts set the direction of the arrows of causality, and some weights corresponding to some extent to the force of the causality.

Therefore, these weighs transformed into probabilities are useful to compute the probabilities of the nodes IT, ID and TTR on Noisy Or variable assumption.

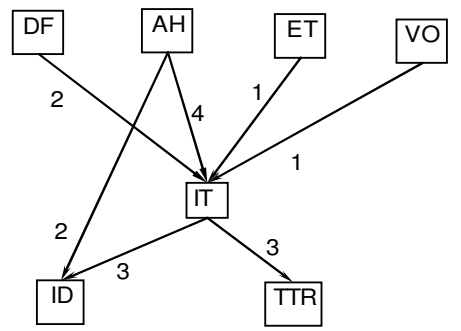

$1-->$ certain $(100 \%)$

$2-->$ probable $(80 \%)$

$3-->50 \%$

4-->uncertain (25\%)

5--> improbable $(15 \%)$

6-->impossible (0\%)

Fig 12 Causal graph deducted from experts information with corresponding arc strength meaning.

In fact the estimation of all the combinations by an expert would be very tiresome. For example for a binary node, $\mathrm{Y}$ with four parents $X$, it should be necessary for the experts to estimate $2^{4}=16$ probabilities. That becomes unrealistic on the scale of a complex graph. As suggested by Finn V Jensen in his book Bayesian Networks and Decision Graphs [11], in such a case it is possible to make the assumption of the variable Noisy-Or . The Noisy-Or variable aims to simplifying the calculation of all the combinations. For binary variables and on the assumption that event "Xi causes $\mathrm{Y}$ " either independent of the events " $\mathrm{Xj}$ causes $\mathrm{Y}$ " for $\mathrm{i}$ different from $\mathrm{j}$, The Noisy -Or assumption gives: $p(Y / X)=1-\prod_{i / X i \in X p}(1-p i)$

Thus for a node $\mathrm{Y}$ with $\mathrm{N}$ parents $\mathrm{X}, \mathrm{N}$ probabilities will be specified instead of $2^{\mathrm{N}}$ probabilities. In addition to this calculation, the following assumption is made: When all the parents $X$ are false, the probability of having the result "false" is 0.9 instead of 1 , because we are not sure that all cases have been considered. The literature in this case, proposes to add a leaky node that is always activated on "true". This method is not followed because it contributes to increase CPT length. The use of Noisy-Or assumption for IT and ID nodes is not really necessary because the dimension of the CPT for these two variables are not high. However, the resultant CPT for these two variables, by making this assumption was close to those expected by the experts.

C. Results:

1) Diagnosis analysis.
Let us consider the case where the client observes that his switchboard is failing but still operating. For instance, he observes a tripping of thermal release (TTR=true) and an insulation degradation (ID=true). Therefore, he wants to know the failures cause. The Bayesian network is then questioned about effects toward causes. This leads to the results in fig 13.

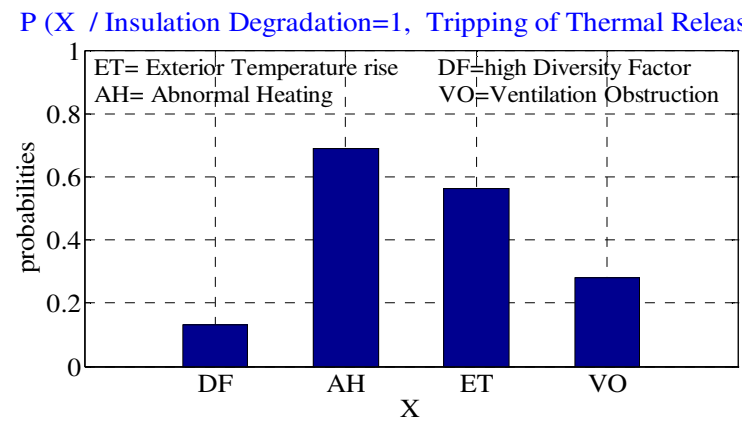

Fig 13 Inference to diagnose a failure

Although the results say that an abnormal heating $(\mathrm{AH})$ is the most probable cause, an increase of the exterior temperature (ET) is also a probable cause since the two probabilities do not differ so much. In this case, we want to know the true cause. Therefore, the variable which is the most cost effective to be checked, should be investigated. In this case, AH could not be checked without stopping the process supplied by the LV switchboard, leading to high cost.

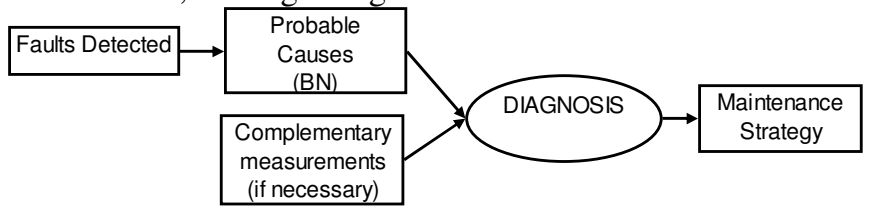

Fig 14 help for diagnosing principle scheme.

In this case it is more cost effective to check if the exterior temperature is high, for example by checking the weather report. Afterward, an effective maintenance strategy can be implemented according to result of the weather report. As can be noticed, Bayesian Network is a tool for focusing our attention on the main causes to check.

2) Risks analysis purpose:

In the case where the client does not notice any failure of the system, but wants to know the risks of defaults taking into account the environment of the system and its operating condition, BN can be used to achieve this aim.

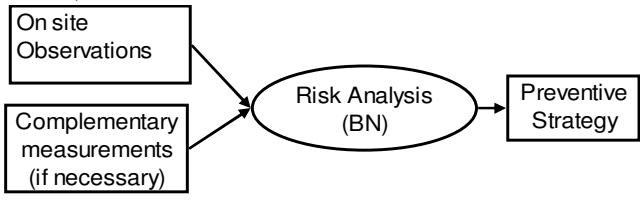

Fig 15 Risk analysis principle scheme

The graph is then questioned by causes towards effects. For instance, the client knows that the ventilation does not work well, the question it can ask himself is: Is it risky for the plant? The implemented BN can answer this question. Fig 16 shows that, there is about $70 \%$ of chance that an insulation degradation (ID) appears. That can be risky for the client to let its LV switchboard without doing anything. 
Therefore, it should be decided to repair the ventilation as soon as possible.

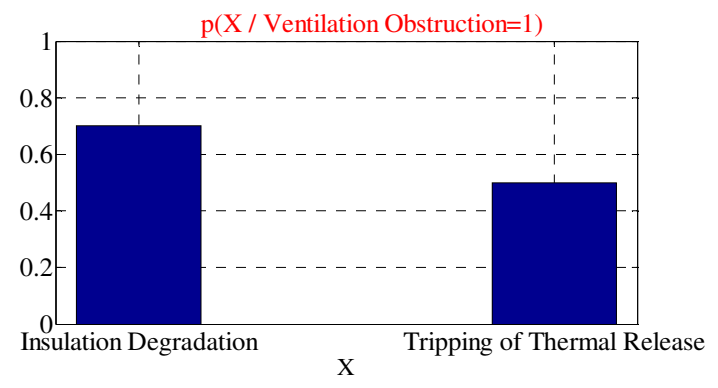

Fig 16 Inference for risk analysis.

D. The use of $B N$ with learning process.

When constructing a Bayesian network, it is not always possible to be certain of the correctness of the chosen conditional probabilities tables. It is often the case that experts in design tend to overestimate the reliability of the equipment that they design. Therefore, we want to build a system that automatically adapts the probabilities tables (Fig17).

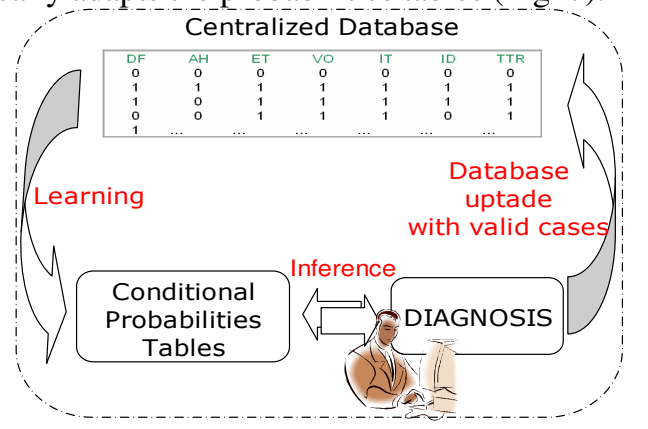

Fig 17 Automatically update of CPT.

A learning process could accomplish this using a database. Learning conditional probabilities from database is a wellknown concept. This is well explained in [12]. In the case that all the variables are observed, one of the simple ways for learning probabilities is statistical learning [13]. For instance, according to statistical learning, the calculation of the conditional probability from a database $p(I D=1 / A H=1, I T=1)$

$$
\text { is given by: } \frac{N_{I D=1, A H=1, I T=1}}{N_{I D=1, A H=1, I T=1}+N_{I D=0, A H=1, I T=1}}
$$

where $N_{I D=1, A H=1, I T=1}$ is the amount of time the combination $\mathrm{ID}=1, \mathrm{AH}=1, \mathrm{IT}=1$ occurs, and $N_{I D=0, A H=1, I T=1}$, the amount of time the combination $\mathrm{ID}=0, \mathrm{AH}=1, \mathrm{IT}=1$ occurs. Most of the time, in practical problems, there are some unobserved variables. The databases are then incomplete. In this case, there are some methods for learning, based on the estimates of the missing parameters. The most used method is the ExpectationMaximization (EM) algorithm [13]. The centralized database will contain all the encountered cases that the experts will have validated the coherence and logic before registering them into the database. This allows a diagnosis of a switchboard by using the cases encountered in other switchboards. The database could be initialized with some samples whose distribution reflects the probabilities given by the experts. The higher the initial samples size, the higher the probabilities will be resistant to changes.

\section{CONCLUSION}

This paper has presented a combined, local detection of failure, and global approach for LV switchboards diagnosis. The results of some experiments leading to the right placement of sensors, have been shown. A method of detection of failures based on comparison with a healthy model, in order to raise alarms with electrical joint failure, has been presented. The test of this method on a switchboard in a real-life situation gives encouraging results. Concerning the diagnosis stage, we use a Bayesian network that is a suitable technique to automate the probabilistic way of thinking of the experts. A concrete implementation of a part of the whole switchboard Bayesian network shows that this method can be a useful tool for the diagnosis and the risk analysis too. A major benefit of using Bayesian Network is that it allows easily taking into account the experience feedback for updating the conditional probabilities with learning process (fig 17). The encouraging results, showed in this paper enable us to believe in the feasibility of this system of detection and diagnosis.

\section{ACKNOWLEDGEMENTS}

The authors gratefully acknowledge Albert Foggia, Frederic Dumas, Jean-Pierre Rognon, for their assistance and Pascal Lepretre, Christophe Kilindjian, Didier Van-dooren, for the expertise information.

\section{REFERENCES}

[1] Kahan N'guessan, Eric Jouseau , Gilles Rostaing, Florence François "A new approach for local detection of failures and global diagnosis of LV switchboards." IEEE International Conference on Industrial Technologie, Mumbai, December 2006.

[2] IEC 60.943, section 3, Ageing mechanisms of contacts and connection terminals, page 31 .

[3] J.F. SACADURA - Initiation aux Transferts Thermiques - Tech \& Doc, Paris 1993.

[4] L. Féchant, Le contact électrique, tome 2 : phénomènes physiques et matériau, Paris, Hermès, 1995. Chapitre 1.

[5] J.Pearl, Probabilistic Reasoning in Intelligent Systems, Morgan Kaufmann, 1988.

[6] Roland Auber Tableaux et armoires, Technique de l'ingénieur, 1997. www.techniques-ingenieur.fr/dossier/tableaux_et_armoires/D5160

[7] Christophe Kilindjian, Thermal study of LV electric switchboards, www.schneiderelectric.com/cahier_technique/en/abstracts/thermal_study _LV_switchboards.htm

[8] Olivier Bouju dependability and LV switchboards Cahier technique ${ }^{\circ} 156$ www.schneiderelectric.com/cahier_technique/en/abstracts/dependability_ LV_switchboards.htm

[9] Les cahiers GIMELEC, Tableaux électriques basse tension $\mathrm{n}^{\circ} 4$ : "La maîtrise des effets thermiques". www.gimelec.fr/techf.htm

[10] Murphy, Bayes Net Toolbox for Matlab, www.cs.berkeley.edu/ murphyk /Bayes/bnt.html

[11] FinnV.Jensen, Bayesian Networks and decision graph, Statistics for engineering and information science Springer 2001,section2.

[12] Heckerman, A Tutorial on Learning with Bayesian Networks, Technical report Microsoft Research MSR-TR-95-06, 1996.

[13] Patrick Naïm, Pierre-henri wuillemin, Philippe leray, Olivier Pourret, Anna Becker, Réseaux bayésiens, Eyrolles 2004.

[14] Claus Skaanning, Finn V. Jensen, Uffe Kjærulff, Paul Pelletier \& Lasse Rostrup-Jensen, Printing System Diagnosis A Bayesian Network Application Ninth International Workshop on Principles of Diagnosis, , Massachusetts USA, 1998. 